
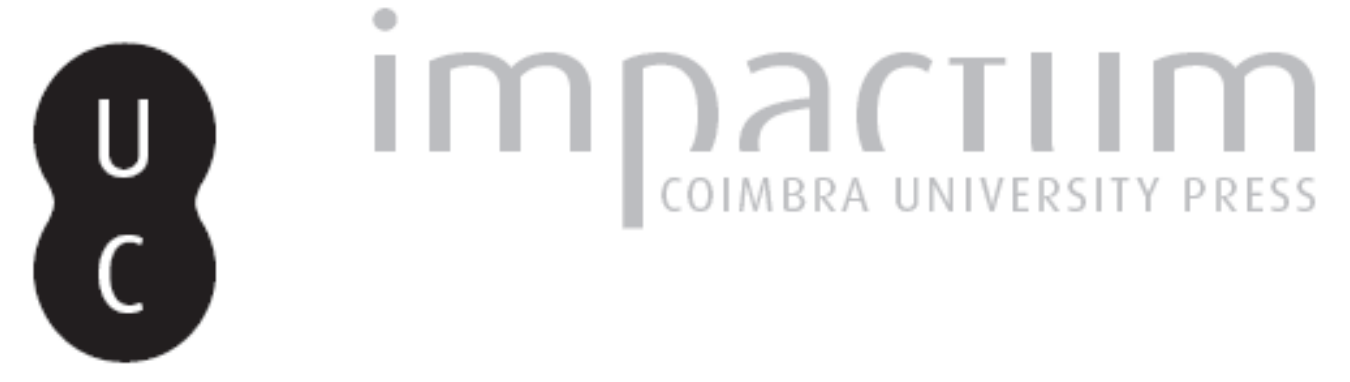

\title{
Risco de stress térmico num ambiente quente em contexto industrial
}

Autor(es): $\quad$ Morgado, Mariana; Talaia, Mário; Teixeira, Leonor

Publicado por: Associação Portuguesa de Riscos, Prevenção e Segurança; Imprensa da Universidade de Coimbra

URL

persistente:

URI:http://hdl.handle.net/10316.2/38069

DOI:

DOI:http://dx.doi.org/10.14195/1647-7723_22_16

Accessed : $\quad$ 26-Apr-2023 13:46:45

A navegação consulta e descarregamento dos títulos inseridos nas Bibliotecas Digitais UC Digitalis, UC Pombalina e UC Impactum, pressupõem a aceitação plena e sem reservas dos Termos e Condições de Uso destas Bibliotecas Digitais, disponíveis em https://digitalis.uc.pt/pt-pt/termos.

Conforme exposto nos referidos Termos e Condições de Uso, o descarregamento de títulos de acesso restrito requer uma licença válida de autorização devendo o utilizador aceder ao(s) documento(s) a partir de um endereço de IP da instituição detentora da supramencionada licença.

Ao utilizador é apenas permitido o descarregamento para uso pessoal, pelo que o emprego do(s) título(s) descarregado(s) para outro fim, designadamente comercial, carece de autorização do respetivo autor ou editor da obra.

Na medida em que todas as obras da UC Digitalis se encontram protegidas pelo Código do Direito de Autor e Direitos Conexos e demais legislação aplicável, toda a cópia, parcial ou total, deste documento, nos casos em que é legalmente admitida, deverá conter ou fazer-se acompanhar por este aviso.

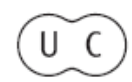




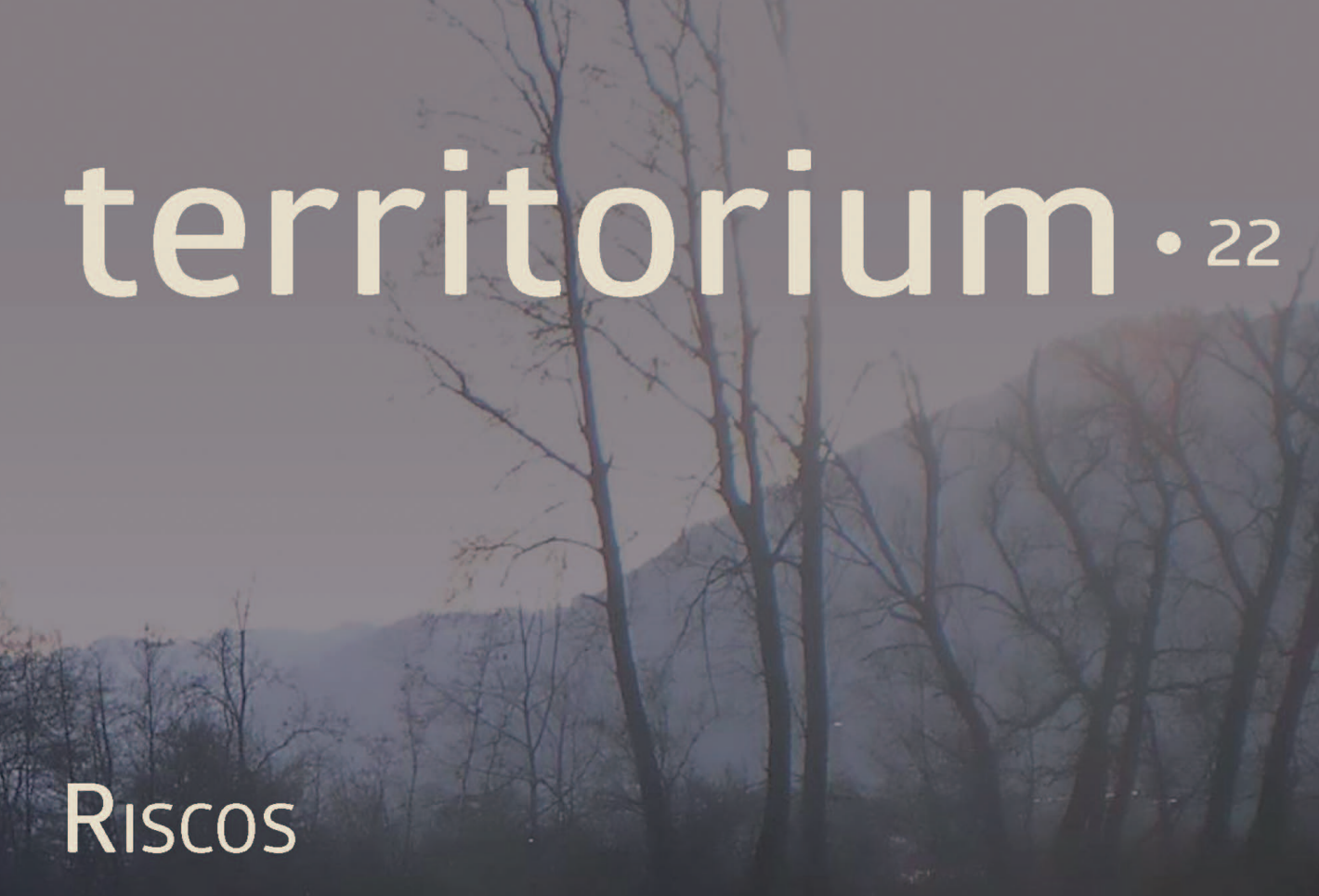

\section{TERRITÓRIOS DE CONVERGÊNCIA}

- Imprensa da Universidade de Coimbra Associação Portuguesa de:Riscos, Prevenção e Segurança 


\title{
RISCO DE STRESS TÉRMICO NUM AMBIENTE QUENTE EM CONTEXTO INDUSTRIAL*
}

THE RISK OF THERMAL STRESS REGARDING HOT ENVIRONMENTS IN INDUSTRIES

\author{
Mariana Morgado \\ DEGEI, Universidade de Aveiro \\ marianafmorgado@ua.pt
}

Mário Talaia

DFIS-CIDTFF, Universidade de Aveiro mart@ua.pt

Leonor Teixeira

DEGEI-IEETA, Universidade de Aveiro lteixeira@ua.pt

\section{RESUMO}

O desconforto térmico é uma causa de insatisfação no trabalho fortemente associada a riscos de acidentes de trabalho. É neste contexto que o presente trabalho se insere, tendo como objetivo, através de índices térmicos, a identificação do padrão térmico dos espaços em estudo e dos postos de trabalho com maior risco a stress térmico, bem como ao conhecimento das sensações térmicas dos trabalhadores. O Departamento de Higiene e Segurança das indústrias estudadas valorizou os resultados para criar medidas que satisfaçam as necessidades em termos de conforto.

Palavras-chave: Desconforto térmico, índices térmicos, padrão térmico, EsConTer, ITH.

\section{ABSTRACT}

Thermal discomfort is a cause of work dissatisfaction related to work accidents risk. This paper aims to identify, regarding thermal indexes application, the thermal patterns of the spaces in study, the most critical workstations as well as the workers thermal sensation. The Hygiene and Safety Department of the industries in study valorized the results in order to satisfy workers comfort needs.

Keywords: Thermal discomfort, thermal indexes, thermal pattern, EsConTer, ITH.

\section{RESUMEN}

Riesgo de estrés térmico en un ambiente caluroso en contexto industrial - La incomodidad térmica es una causa de la insastifacción laboral, fuertemente asociada con el riesgo de accidentes de trabajo. El actual estudio se desarrolla en este contexto y tiene como objectivo, através de los índices térmicos, la identificación del patrón térmico de las áreas de estúdio y los trabajos con mayor riesgo de estrés por calor, así como el conocimiento de las sensaciones térmicas de los trabajadores. El Departamento de Salud y Seguridad de las empresas estudiadas ha apreciado los resultados obtenidos para crear medidas ayuden a promover la comodidad de sus trabajadores.

Palabras clave: Incomodidad térmica, índice de calor, patrón de calor, EsConTer, ITH.

\section{RÉSUMÉ}

Le risque de stress thermique sur les environnements chauds dans les industries - L'inconfort thermique est une cause de mal-être au travail et un facteur de risque d'accidents du travail. Cet article a pour but d'identifier, grâce à des indices thermiques, les modèles thermiques des lieux étudiés, les postes de travail les plus critiques ainsi que la connaissance du ressenti thermique des opérateurs. Les départements Hygiène et Sécurité des industries étudiées ont utilisé les résultats afin de mettre en place des mesures pour satisfaire les besoins en confort des opérateurs.

Mots-clé: Inconfort thermique, indices thermiques, modèles thermiques, EsConTer, ITH.

* O texto deste artigo corresponde a uma comunicação apresentada no III Congresso Internacional, I Simpósio Ibero-Americano e VIII Encontro Nacional de Riscos, tendo sido submetido em 30-01-2015, sujeito a revisão por pares a 30-04-2015 e aceite para publicação em 24-07-2015.

Este artigo é parte integrante da Revista Territorium, $n .{ }^{\circ} 22,2015,{ }^{\circ}$ RIscos, ISSN: 0872-8941. 


\section{Introdução}

O tema do conforto térmico (condição mental que expressa satisfação com o ambiente térmico envolvente) tem sido investigado nos mais variados contextos, no sentido de procurar a maximização do conforto térmico de espaços interiores/exteriores, associado à necessidade de redução de consumos energéticos e ao desenvolvimento de soluções arquitetónicas que garantam a segurança, o conforto e a saúde dos indivíduos (M. Castilla et al., 2011; D. Daum et al., 2011; J. Liu et al., 2012; M. Morgado et al., 2014).

É sabido que os indivíduos passam a maior parte do seu tempo em ambientes interiores, nomeadamente laborais (V. Felix el al., 2010; P. Hoppe, 2002). É importante que os indivíduos possam usufruir, nesses ambientes, de uma sensação térmica de conforto (T. Akimoto el al. 2010). Contudo, para a climatização de espaços interiores é necessário ter em conta também os espaços exteriores em redor, uma vez que estes exercem influência através de parâmetros termohigrométricos sobre o ambiente dos espaços interiores (R. Yao et al., 2009).

No que diz respeito aos ambientes laborais, segundo (C. Huizenga et al., 2006), o desconforto térmico é considerado uma das maiores causas de insatisfação no trabalho, realçando as várias relações que têm vindo a ser abordadas entre o conforto, saúde, controlo do ambiente de espaços interiores e produtividade ( $P$. M. Bluyssen et al., 2011; T.C. Riniolo et al., 2006). 0 estudo do ambiente térmico no interior dos locais de trabalho está associado à ergonomia do trabalho e saúde ocupacional, "devendo atender à necessidade de aquisição de condições aceitáveis em termos de saúde e conforto e ser adequado ao organismo humano, em função de diversos fatores como os processos produtivos, os métodos de trabalho e a carga física a que os trabalhadores são submetidos" (I. Tavares, 2014).

Segundo (R. Emmanuel, 2005) o tema do conforto térmico começou a ser estudado por arquitetos e designers como consequência da urbanização. No entanto, foi com os estudos de (P. Fanger, 1972) que a investigação neste domínio ganhou relevo e seguidores, tanto na área da meteorologia, como nas áreas da medicina, da arquitetura, da engenharia, entre outras.

O conforto térmico é uma reação complexa a um conjunto de parâmetros ambientais, podendo ser definido como a satisfação de um indivíduo quando exposto a um determinado ambiente térmico, ou seja, uma sensação térmica neutra (ASHRAE, 2001; ASHRAE 55, 2004; T. T. Chow et al., 2010).

A sensação térmica (indicação da perceção da transferência de energia sob a forma de calor entre o corpo e o ar envolvente) é uma característica muito própria de cada indivíduo, que está relacionada com o balanço térmico do corpo humano e, por isso, é dependente é influenciada por vários fatores relacionados com o ambiente térmico (conjunto de variáveis termohigrométricas) e com fatores pessoais, sejam eles físicos, psicológicos e/ou fisiológicos ( $M$. Castilla et al., 2011). Com base nestes pressupostos as diferentes zonas de conforto térmico dependem de componentes subjetivas e individuais ou quaisquer especificidades locais/contexto (T. Starling et al., 2013). Por outro lado, o stress térmico pode ser definido como o estado de insatisfação de um indivíduo quando exposto a ambientes térmicos extremos de frio ou calor (M. Morgado et al., 2014; L. Teixeira et al., 2014).

Quando exposto a estes dois tipos de ambientes o organismo humano desencadeia ações de regulação adequadas a partir do sistema termorregulador do organismo e do comportamento. Contudo, em determinadas situações, o permanente contacto com este tipo de ambientes pode desencadear o risco de doenças e, em casos extremos pode até levar à morte (ASHRAE, 2001). Segundo I. Tavares (2014) “a situação ideal, corresponde a um ambiente neutro que ocorre quando um indivíduo está numa condição de equilíbrio com o ambiente que o rodeia, sem que haja um esforço sensível para a manutenção da temperatura dos tecidos constituintes do corpo".

São várias as metodologias aplicadas a estudos de ambientes térmico em espaços fechados e estudos de sensação térmica dos trabalhadores, no sentido de se criarem ambientes que satisfaçam o maior número possível de ocupantes (K. Parsons, 2000). A TABELA I resume alguns estudos com aplicação dos mais comuns índices térmicos, em termos do seu objetivo, contexto de aplicação e variáveis a recolher.

O presente trabalho, desenvolvido em contexto industrial no âmbito de duas empresas de ramos distintos, tem como principal objetivo identificar o padrão térmico de espaços fechados e, consequentemente, os postos de trabalho com maior risco de stress térmico quente, bem como conhecer as sensações térmicas dos trabalhadores afetos a esses espaços. As empresas envolvidas no estudo têm associados ambientes térmicos quentes, tendo os dados sido recolhidos na estação de primavera. Pretendese, com isto, promover o desenvolvimento de medidas corretivas que permitam criar as condições de trabalho que melhor satisfaçam os ocupantes do espaço industrial, em locais com características de ambiente quente.

\section{Ambiente Térmico Quente}

De acordo com (B. Meles, 2012) "o stress térmico em ambiente térmico quente ocorre quando os parâmetros ambientais, o nível de vestuário e o nível 
TABELA I - Índices térmicos e variáveis recolhidas para o estudo do ambiente térmico e sensação térmica.

$T_{A B L E} I$ - Thermal indexes and variables collected for thermal environment and thermal sensation study.

\begin{tabular}{|c|c|c|c|c|c|}
\hline \multirow[b]{2}{*}{ Autor } & \multirow[b]{2}{*}{ Contexto } & \multirow[b]{2}{*}{ Objetivos } & \multicolumn{2}{|c|}{ Índices térmicos } & \multirow[b]{2}{*}{ Variáveis recolhidas } \\
\hline & & & $\begin{array}{c}\text { Ambiente } \\
\text { térmico }\end{array}$ & $\begin{array}{c}\text { Sensação } \\
\text { térmica }\end{array}$ & \\
\hline $\begin{array}{l}\text { (J. Nogueira } \\
\text { et al., 2014) }\end{array}$ & $\begin{array}{l}\text { AeroStep } \\
\text { (sala de } \\
\text { fitness) }\end{array}$ & $\begin{array}{l}\text { Avaliar a } \\
\text { sensação térmica } \\
\text { das praticantes } \\
\text { de AeroStep }\end{array}$ & $\begin{array}{l}\text { EsConTer; ITH } \\
\text { (índice temp. e } \\
\text { humidade) }\end{array}$ & $\begin{array}{l}\text { EsConTer; Escala } \\
\text { térmica de cores }\end{array}$ & $\begin{array}{l}\text { Temperatura do ar; } \\
\text { humidade relativa do ar; } \\
\text { sensação térmica real } \\
\text { (questionário) }\end{array}$ \\
\hline $\begin{array}{c}\text { (R. Bakar } \\
\text { et al., 2010) }\end{array}$ & $\begin{array}{l}\text { Indústria } \\
\text { automóvel } \\
\text { da Malásia } \\
\text { (espaço } \\
\text { interior) }\end{array}$ & $\begin{array}{l}\text { Determinar } \\
\text { o conforto } \\
\text { térmico dos } \\
\text { trabalhadores da } \\
\text { empresa }\end{array}$ & $\begin{array}{l}\text { WBGT (Wet } \\
\text { Bulb Globe } \\
\text { Temperature) }\end{array}$ & $\begin{array}{l}\text { PMV (predicted } \\
\text { mean vote); } \\
\text { PPD (predicted } \\
\text { percentage } \\
\text { dissatisfied); } \\
\text { escala sétima de } \\
\text { sensação térmica } \\
\text { de ASHRAE }\end{array}$ & $\begin{array}{l}\text { Velocidade do ar; } \\
\text { Humidade relativa do } \\
\text { ar; temperatura média } \\
\text { radiante; temperatura } \\
\text { do ar; nível de } \\
\text { atividade; isolamento do } \\
\text { vestuário }\end{array}$ \\
\hline $\begin{array}{l}\text { (D. Pereira, } \\
\text { 2013) }\end{array}$ & $\begin{array}{l}\text { Salas de } \\
\text { aula de } \\
\text { escolas } \\
\text { públicas }\end{array}$ & $\begin{array}{l}\text { Avaliar o } \\
\text { desempenho } \\
\text { da ventilação } \\
\text { natural para a } \\
\text { promoção de } \\
\text { conforto térmico } \\
\text { de salas de } \\
\text { aula de escolas } \\
\text { públicas }\end{array}$ & & $\begin{array}{l}\text { PMV; PPD; } \\
\text { escala sétima de } \\
\text { sensação térmica } \\
\text { de ASHRAE }\end{array}$ & $\begin{array}{l}\text { Temperatura do } \\
\text { termómetro húmido; } \\
\text { temperatura do ar; } \\
\text { temperatura do globo; } \\
\text { sensação térmica } \\
\text { (questionário) }\end{array}$ \\
\hline $\begin{array}{l}\text { (T.P. Lin } \\
\text { et al. 2010) }\end{array}$ & $\begin{array}{l}\text { Espaço } \\
\text { exterior- } \\
\text { Campus da } \\
\text { National } \\
\text { Formosa } \\
\text { University, } \\
\text { Taiwan }\end{array}$ & $\begin{array}{l}\text { Análise do efeito } \\
\text { da sombra em } \\
\text { ambientes } \\
\text { exteriores, } \\
\text { baseado no } \\
\text { intervalo de } \\
\text { conforto dos } \\
\text { habitantes de } \\
\text { Taiwan. }\end{array}$ & $\begin{array}{l}\text { PET } \\
\text { (physiologically } \\
\text { equivalent } \\
\text { temperature) }\end{array}$ & $\begin{array}{l}\text { Escala sétima de } \\
\text { sensação térmica } \\
\text { de ASHRAE }\end{array}$ & $\begin{array}{l}\text { Temperatura do globo; } \\
\text { temperatura do ar; } \\
\text { humidade relativa do } \\
\text { ar; temperatura média } \\
\text { radiante; velocidade } \\
\text { do ar; isolamento do } \\
\text { vestuário; metabolismo; } \\
\text { SVF (sky view factor) }\end{array}$ \\
\hline $\begin{array}{l}\text { (T. Akimoto } \\
\text { et al., 2010) }\end{array}$ & Escritório & $\begin{array}{l}\text { Estudo da } \\
\text { influência do } \\
\text { comportamento } \\
\text { e controlo da } \\
\text { climatização } \\
\text { na sensação de } \\
\text { conforto dos } \\
\text { trabalhadores. }\end{array}$ & & $\begin{array}{l}\text { Escala sétima de } \\
\text { sensação térmica } \\
\text { de ASHRAE }\end{array}$ & $\begin{array}{l}\text { Temperatura horizontal; } \\
\text { humidade relativa } \\
\text { do ar; temperatura } \\
\text { vertical; velocidade do } \\
\text { ar; temperatura média } \\
\text { radiante; isolamento do } \\
\text { vestuário; metabolismo; } \\
\text { sensação térmica } \\
\text { (questionário) }\end{array}$ \\
\hline
\end{tabular}

Fonte: Retirada de M. Morgado et al., 2014. Source: Retrieved from M. Morgado et al., 2014.

de metabolismo interagem e provocam um aumento gradual da temperatura interna corporal, levando a que este ultrapasse um determinado valor".

A tolerância de indivíduos a ambientes quentes varia consoante a sensibilidade à temperatura e perdas de energia sob a forma de calor através da transpiração e da movimentação através do sangue desde o interior do corpo humano até à superfície da pele (ASHRAE, 2001).

K. Parsons (2003) refere que o desconforto térmico provocado por ambientes demasiado quentes apresenta riscos comportamentais para performance cognitiva, para o rendimento e desempenho profissional e para a vitalidade do corpo humano. Alguns sintomas provocados por ambientes demasiado quentes são: dificuldade no processamento de informação no cérebro; alterações psicosensoriais; inquietação e perda de concentração; sonolência; aumento do suor; aumento da temperatura superficial da pele; tonturas; e desmaios (M. E. Araújo et al., 2013; B. Meles, 2012; I. P. Pinheiro, 2011; ASHRAE, 2001).

A aclimatização é o estado resultante de um processo de adaptação fisiológica que aumenta a tolerância do indivíduo quando é exposto a um dado ambiente térmico extremamente quente por um período de tempo suficientemente longo (I. P. Pinheiro, 2011).

\section{Metodologia}

0 presente estudo foi desenvolvido em duas industriais com realidades distintas: a indústria 1 associada ao ramo metalúrgico; a indústria 2 associada ao ramo vidreiro. No entanto, ambas estão associadas a risco de stress térmico, devido às características de ambiente térmico quente. 
A metodologia aplicada no estudo levado a cabo nas duas indústrias supra mencionadas, será explicada em torno de três subcapítulos: (i) identificação das zonas de risco a stress térmico; (ii) avaliação da sensação térmica real dos trabalhadores; e (iii) sugestões de medidas corretivas.

\section{Identificação das zonas de risco a stress térmico}

Para a identificação dos locais com maior risco a stress térmico foram considerados e analisados os layouts de ambas as indústrias em formato papel e, posteriormente, foram traçadas as rotas que guiaram a recolha, bem como definidos os pontos de observação onde foram feitas as medições (fig. 1).

A recolha dos dados (medições) foi realizada durante dois períodos, de manhã e à tarde, de forma a compreender a influência do ciclo diurno da radiação solar no ambiente térmico interior do espaço em estudo. Inicialmente, em cada período foram feitos dois circuitos com sentidos opostos. A pertinência da execução destes dois circuitos reside na tentativa de mostrar que o ambiente térmico da nave industrial não depende da opção do circuito. Em todas as zonas de recolha de dados foram utilizados os aparelhos de medida 'Center 317 - temperature humidity meter' e 'Testo 435-4' com uma sonda Testo. Os dados registados pelos dois instrumentos de medida geraram o mesmo padrão, o que confirmou a sua calibração. Relativamente aos parâmetros recolhidos, foram recolhidos valores de temperatura do ar e humidade relativa do ar.

Por forma a autenticar os valores recolhidos nas zonas de observação exteriores ao espaço em estudo, foram também recolhidas cartas meteorológicas e gráficos relativos à temperatura do ar e humidade relativa do ar do site do Instituto Português do Mar e da Atmosfera ipma (http://www.ipma.pt/pt/).

Após a recolha dos dados e autenticação dos mesmos, aplicaram-se dois índices térmicos, o ITH (S. Nieuwolt, 1977) e o EsConTer (M. Talaia et al., 2009). Estes dois índices térmicos foram gerados através de algoritmos desenvolvidos em Matlab, apresentando gráficos de superfície de cor que permitiram identificar os locais de trabalho com maior risco a stress térmico.

\section{Índice EsConTer}

O Índice EsConTer, desenvolvido por (M. Talaia et al., 2009), tem como objetivo prever a sensação térmica de um ambiente fechado. Este índice tem estado presente em inúmeras conferências nacionais e internacionais, onde tem sido reconhecido o seu valor no que diz respeito a uma previsão de um ambiente térmico ser muito próxima da sensação térmica real de um indivíduo/ trabalhador. 0 mesmo prevê a sensação térmica baseada
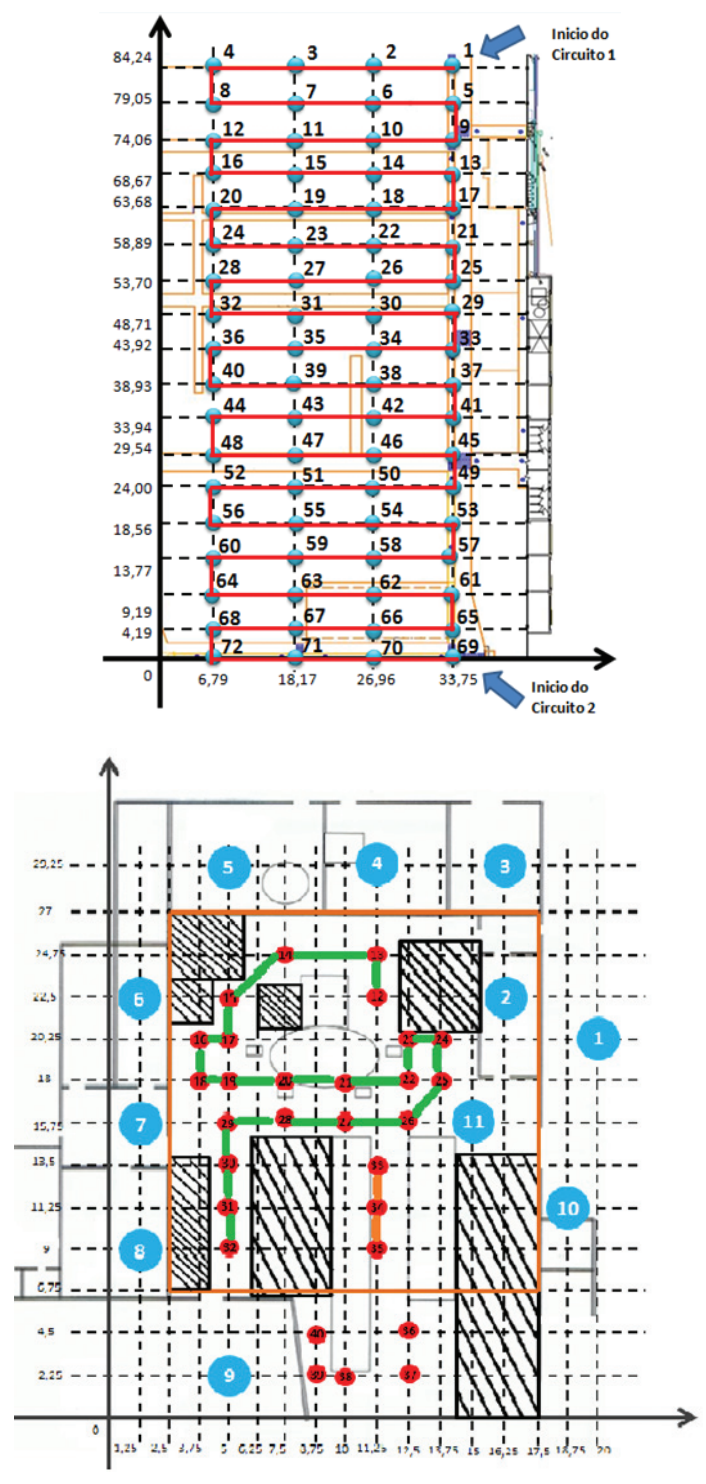

Fig. 1- Layouts e pontos de observação na indústria 1 e na indústria 2.

Fig. 1- Layouts and points of observation in industry 1 and industry 2.

numa escala térmica de cores que é concordante com a escala sétima de sensação térmica de ASHRAE ( $M$. Talaia et al., 2008). A fig. 2 representa a escala de cores utilizada para o registo da sensação térmica real.

Tal como a escala sétima de sensação térmica de ASHRAE, o resultado do índice EsConTer está associado a um intervalo de valores adimensionais de sensação térmica que varia entre $-3 \mathrm{e}+3$, caracterizado nos

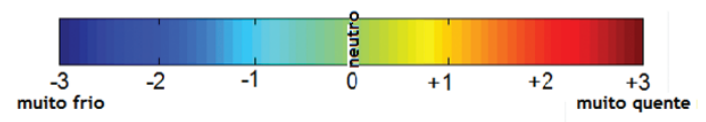

Fig. 2 - Escala térmica de cores (M. Talaia et al., 2008).

Fig. 2 - Thermal colour scale (M. Talaia et al., 2008). 
extremos por stress térmico extremo de frio e de calor, respetivamente, associados às cores "azulescuro" e "vermelho escuro". Os valores intermédios correspondem a outras sensações térmicas na escala, sendo que o valor 0 , correspondente a uma sensação de conforto térmico (condição térmica neutra), que está equidistante a ambos os extremos explicados.

0 índice EsConTer considera para efeitos de cálculo a temperatura do ar e a temperatura do termómetro húmido e a sua expressão tem o aspeto,

$$
\text { EsConTer }=-3,75+0,103\left(T_{a}+T_{w}\right)
$$

onde $\mathrm{T}_{\mathrm{a}}$ representa a temperatura do $\operatorname{ar}\left({ }^{\circ} \mathrm{C}\right)$ e $\mathrm{T}_{\mathrm{w}}$ a temperatura do termómetro húmido $\left({ }^{\circ} \mathrm{C}\right)$.

\section{Índice ITH}

0 índice temperatura-humidade, ITH, conhecido por índice de desconforto foi desenvolvido por (E.C. Thom, 1959) e posteriormente modificado por (S. Nieuwolt, 1977) e é calculado a partir de,

$$
\mathrm{ITH}=0,75 \mathrm{~T}_{\mathrm{a}}+\mathrm{T}_{\mathrm{a}}(\mathrm{HR} / 500)
$$

onde $\mathrm{T}_{\mathrm{a}}$ representa a temperatura do $\operatorname{ar}\left({ }^{\circ} \mathrm{C}\right)$ e $\mathrm{HR}$ a humidade relativa do ar (\%).

A interpretação deste índice é feita de acordo com (R. Emmanuel, 2005), como mostra a TABELA II.

TABELA II - Valores dos limites do ITH

TABLE II - Range of values for THI.

\begin{tabular}{|c|c|}
\hline \multicolumn{2}{|c|}{ ITH } \\
\hline $21{ }^{\circ} \mathrm{C} \leq \mathrm{ITH} \leq 24^{\circ} \mathrm{C}$ & $\begin{array}{c}100 \% \text { dos indivíduos estão } \\
\text { termicamente confortáveis }\end{array}$ \\
\hline $24{ }^{\circ} \mathrm{C}<\mathrm{ITH} \leq 26{ }^{\circ} \mathrm{C}$ & $\begin{array}{c}50 \% \text { dos indivíduos estão } \\
\text { termicamente confortáveis }\end{array}$ \\
\hline $\mathrm{ITH}>26^{\circ} \mathrm{C}$ & $\begin{array}{c}100 \% \text { dos indivíduos } \\
\text { estão termicamente } \\
\text { desconfortáveis }\end{array}$ \\
\hline
\end{tabular}

Fonte: adaptada de R. Emmanuel, 2005.

Source: adapted from R. Emmanuel, 2005.

\section{Avaliação da sensação térmica dos trabalhadores}

Nos postos de trabalho selecionados foram recolhidos valores de temperatura do ar e humidade relativa do ar durante dois períodos do dia, manhã e tarde. Cada período do dia foi analisado em dois momentos, no período da manhã às $10 \mathrm{~h} 00$ e $12 \mathrm{~h} 00$ e no período da tarde às $15 \mathrm{~h} 00$ e às 17 h00. Ao mesmo tempo que foram efetuadas as medições foram questionados os trabalhadores, afetos aos postos de trabalho em estudo, com a escala térmica de cores (ver fig. 2). Para responder a este questionário, os trabalhadores apenas tinham que assinalar com uma cruz $(X)$, o local que melhor correspondia à sua sensação térmica aquando da inquirição. A partir desses valores foram gerados gráficos que permitiram comparar a resposta real dos trabalhadores com a sensação prevista dos trabalhadores (dada através do índice EsConTer).

Para além da informação registada na escala térmica de cores, foram também recolhidas informações relativas ao isolamento do vestuário e ao metabolismo, de forma a perceber melhor como se sentiam os trabalhadores ( $P$. Fanger, 1972).

\section{Isolamento do vestuário}

A variável vestuário é bastante importante no estudo do conforto térmico, pois permite perceber a adequação do vestuário de trabalho face às condições do ambiente térmico. $O$ vestuário é também um elemento de elevada importância no conforto térmico uma vez que regula as trocas de energia sob a forma de calor, tal como a massa de suor do corpo humano com o meio ambiente (J. Huang, 2006).

Para a análise da variável vestuário é avaliada a resistência térmica do vestuário que consiste no poder protetor do mesmo (F. A. Rodrigues, 2007). Esta variável é expressa em clo, sendo 1 clo correspondente a $0,155 \mathrm{~m}^{2} .{ }^{\circ} \mathrm{C} / \mathrm{W}$, que representa a resistência térmica oferecida por cada $0,155 \mathrm{~m}^{2}$ do conjunto de roupa vestida, quando a pele coberta arrefece $1^{\circ} \mathrm{C}$ devido à taxa de transferência de energia sob a forma de calor de $1 \mathrm{~W}$ para a superfície exterior da referida roupa (ISO 7730, 2005).

Os valores da resistência térmica do vestuário foram calculados através de valores tabelados e disponíveis na literatura da especialidade (ISO 7730, 2005). Uma alternativa para a determinação da resistência térmica do vestuário é a partir da possibilidade de se usar um manequim térmico, que consiste num instrumento que mede fluxos à escala humana e permite avaliar o calor dissipado pelo corpo humano (N. Djongyang et al., 2010).

O tipo de vestuário usado pelas pessoas varia também consoante as estações do ano. Neste sentido, a (ASHRAE, 2001) especifica zonas de conforto para o verão e para o inverno associados a níveis de resistência térmica de 0,5 clo e 0,9 clo, respetivamente.

\section{Metabolismo}

Segundo (B. Rodrigues, 1978), o metabolismo consiste no conjunto de processos bioquímicos que ocorrem no organismoquandoestecriatecidovivoapartirdesubstâncias nutritivas básicas, transformando-as em energia. 
A taxa de metabolismo por unidade de área significa a energia consumida/utilizada por um ser humano num determinado período de tempo e por unidade de área de pele (ou a quantidade de calor produzida por unidade de tempo por unidade de área de pele). A taxa de metabolismo pode ser expressa em $\mathrm{W} / \mathrm{m}^{2}$ ou em unidades de met. De acordo com a norma internacional (ISO 7730, 2005) 1 met corresponde a uma perda da taxa de energia sob a forma de calor por unidade de área de $58,2 \mathrm{~W} / \mathrm{m}^{2}$, estando associado ao estado de um indivíduo europeu do sexo masculino em repouso com cerca de 1,8 $\mathrm{m}^{2}$ de área de superfície de pele [uma mulher europeia em média apresenta cerca de $1,6 \mathrm{~m}^{2}$ de área de superfície de pele (ASHRAE, 2001)].

Podem distinguir-se dois tipos de metabolismo: (i) o metabolismo de atividade, que resulta do esforço físico humano e da sua atividade; e (ii) o metabolismo basal que é considerado um valor standard igual a $45 \mathrm{~W} / \mathrm{m}^{2} \mathrm{e}$ que corresponde ao estado de repouso do organismo, sem influências térmicas externas e com vestuário termicamente neutro (I. P. Pinheiro, 2011).

Em geral, as taxas de metabolismo associadas às mulheres são cerca de $30 \%$ inferiores à dos homens (ASHRAE, 2001). No entanto, a atividade das pessoas consiste num conjunto diferente de atividades e períodos de descanso ao longo do dia.

Para (V. Candas, 2000) em condições de atividade o calor metabólico produzido pode ser obtido através de,

$$
M=M_{b}+M_{p}+M_{a}
$$

onde $M$ representa a quantidade de calor metabólico produzido na unidade de tempo e por unidade de área $\left(\mathrm{W} / \mathrm{m}^{2}\right), M_{b}$ o metabolismo basal $\left(\mathrm{W} / \mathrm{m}^{2}\right), M_{\mathrm{p}}$ o valor de calor metabólico da postura do ser humano na unidade de tempo e por unidade de área $\left(\mathrm{W} / \mathrm{m}^{2}\right)$ e $\mathrm{M}_{\mathrm{a}}$ o valor de calor metabólico correspondente à atividade na unidade de tempo e por unidade de área $\left(\mathrm{W} / \mathrm{m}^{2}\right)$. Neste trabalho foi usado este método de cálculo do metabolismo e foram consultadas a TABELA III e TABELA IV.

A norma (ISO 7730, 2005) também disponibiliza uma tabela para taxas de metabolismo de algumas atividades.

TABELA III - Valores de metabolismo associados à postura do ser humano.

TABLE III - Metabolism values associated to individuals' posture.

\begin{tabular}{|c|c|c|c|c|}
\hline Postura & Sentado & Agachado & Levantado & $\begin{array}{c}\text { Levantado } \\
\text { e inclinado }\end{array}$ \\
\hline$M_{p}\left(\mathrm{~W} / \mathrm{m}^{2}\right)$ & 10 & 20 & 25 & 30 \\
\hline
\end{tabular}

Fonte: adaptada de N. Djongyang et al., 2010. Source: adapted from N. Djongyang et al., 2010.
TABELA IV - Valores de metabolismo associados à atividade do ser humano.

TABLE IV - Metabolism values associated to individuals' activity.

\begin{tabular}{|c|c|c|c|}
\hline \multicolumn{4}{|c|}{$M_{a}\left(W / m^{2}\right)$} \\
\hline $\begin{array}{l}\text { Tipo de } \\
\text { trabalho }\end{array}$ & Leve & Mediano & Pesado \\
\hline Mãos & $10-22$ & $22-34$ & $34-46$ \\
\hline Um braço & $25-45$ & $45-65$ & $65-85$ \\
\hline Dois braços & $55-75$ & $75-95$ & $95-115$ \\
\hline Corpo & $95-155$ & $155-230$ & $230-330$ \\
\hline
\end{tabular}

Source: adapted from N. Djongyang et al., 2010.

\section{Sugestões de medidas corretivas}

Para locais considerados mais críticos foi utilizada a plataforma CBE Thermal Comfort Tool desenvolvida por (S. Schiavon et al., 2014), que foi criada com o intuito de apoiar o cálculo e visualização do conforto térmico segundo a norma (Standard 55, 2004) e que está disponível gratuitamente no site http://cbe.berkeley. edu/comforttool. Com os resultados desta, é possível facultar a qualquer decisor (por exemplo, designers, arquitetos, engenheiros) um melhor entendimento do conforto térmico aquando da tomada de decisão, como por exemplo, no momento de criar/desenhar um espaço interior. A partir da introdução de alguns inputs, como a temperatura do ar, a humidade relativa do ar, a temperatura média radiante, a velocidade do ar, a temperatura operativa, o metabolismo e o isolamento do vestuário associados a um indivíduo, a plataforma desenha/sugere uma região num gráfico psicométrico associado aos valores da zona de conforto. 0 círculo a vermelho, que aparece na simulação, com um ponto no centro sinaliza no gráfico a zona associada aos dados introduzidos (ambiente térmico).

Tendo em conta os dados recolhidos testou-se esta aplicação com valores de humidade relativa do ar e temperatura do ar resultantes das medições efetuadas e inseriram-se também valores referentes ao isolamento térmico e metabolismo dos trabalhadores afetos ao espaço. Em todos os gráficos gerados por este programa foi considerada uma temperatura média radiante igual à temperatura do ar (temperatura do termómetro seco). Esta plataforma não consegue simular de uma só vez o intervalo de valores recolhidos, por isso, optouse por selecionar algumas regiões com risco a maior desconforto identificadas pelo índice EsConTer (visto que os resultados são apresentados segundo uma escala de -3 $a+3$ de sensação térmica). 0 objectivo desta aplicação foi detectar se os gráficos gerados pela plataforma apresentam a mesma ou semelhante informação que os gerados pelo índice EsConTer, uma vez que a plataforma também apresenta valores na gama da escala sétima de sensação térmica de ASHRAE. 


\section{Resultados}

\section{O caso da Indústria 1}

Após a recolha dos dados (valores de temperatura do ar e humidade relativa do ar) foram gerados gráficos de superfície de cor relativos à temperatura do ar, à humidade relativa do ar e aos dois índices térmicos em estudo, o EsConTer e o ITH, como mostram a fig. 3 e a fig. 4. Estes gráficos, escolhidos de forma arbitrária, representam a informação registada num dia de estudo de primavera, o dia 6 de Maio de 2013.

O eixo das ordenadas e das abcissas representam uma escala relativa à dimensão do espaço, isto é, a distância em metros. Do lado direito das figuras, uma tabela de cores está associada a valores da variável estudada, que cria um determinado padrão de cor.

A fig. 3 representa o padrão para a temperatura do ar e da humidade relativa do ar. As linhas indicadas na figura mostram como o espaço é influenciado pela temperatura do ar e humidade relativa do ar. No gráfico relativo à temperatura do ar, as áreas assinaladas com cor "vermelho escuro" indicam as zonas com temperaturas mais elevadas que sugerem zona de risco. A partir da observação do gráfico da humidade relativa do ar podemos concluir que a região com uma humidade relativa mais baixa corresponde à mesma região com temperatura do ar mais elevada. Esta situação está de acordo com a teoria do ar húmido para espaços fechados, ou seja, se uma variável aumenta a outra diminui. Assim, a zona suscetível a um maior desconforto (risco de stress térmico) sugerida pela fig. 3 corresponde à zona central da nave em estudo, indicando, consequentemente, maior desconforto térmico em postos de trabalho aí localizados.

A fig. 4 diz respeito aos gráficos gerados em Matlab relativos ao índice EsConTer e ao índice ITH. Estes revelam-se concordantes no que diz respeito à área com maior risco de desconforto térmico, a qual é apresentada entre os $40 \mathrm{~m}$ e os $70 \mathrm{~m}$ no eixo dos yy e os $15 \mathrm{~m}$ e os $35 \mathrm{~m}$ no eixo dos $x x$, correspondendo à área de cor "vermelho mais escuro". Esta zona está associada a temperaturas do ar mais elevadas e a humidades relativas do ar mais baixas, de acordo com a fig. 3 .
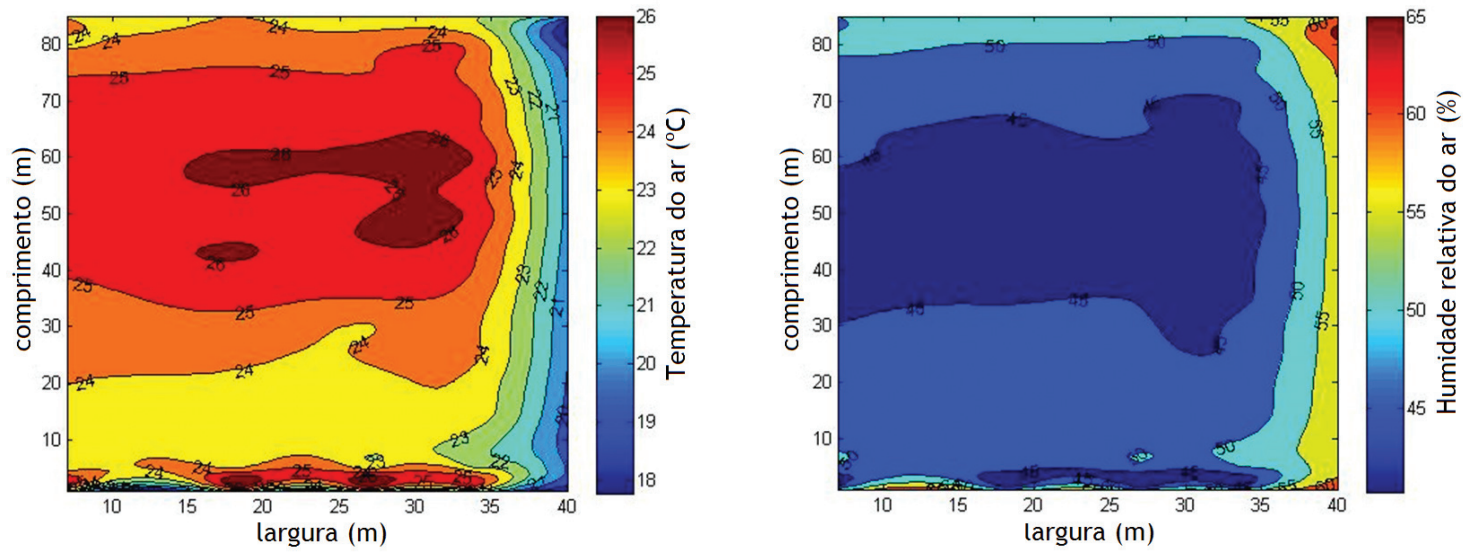

Fig. 3 - Temperatura do $\operatorname{ar}\left({ }^{\circ} \mathrm{C}\right)$ e Humidade Relativa do ar (\%), 6 de Maio de 2013.

Fig. 3 - Air temperature $\left({ }^{\circ} \mathrm{C}\right)$ and air relative humidity (\%), $6^{\text {th }}$ of May 2013.
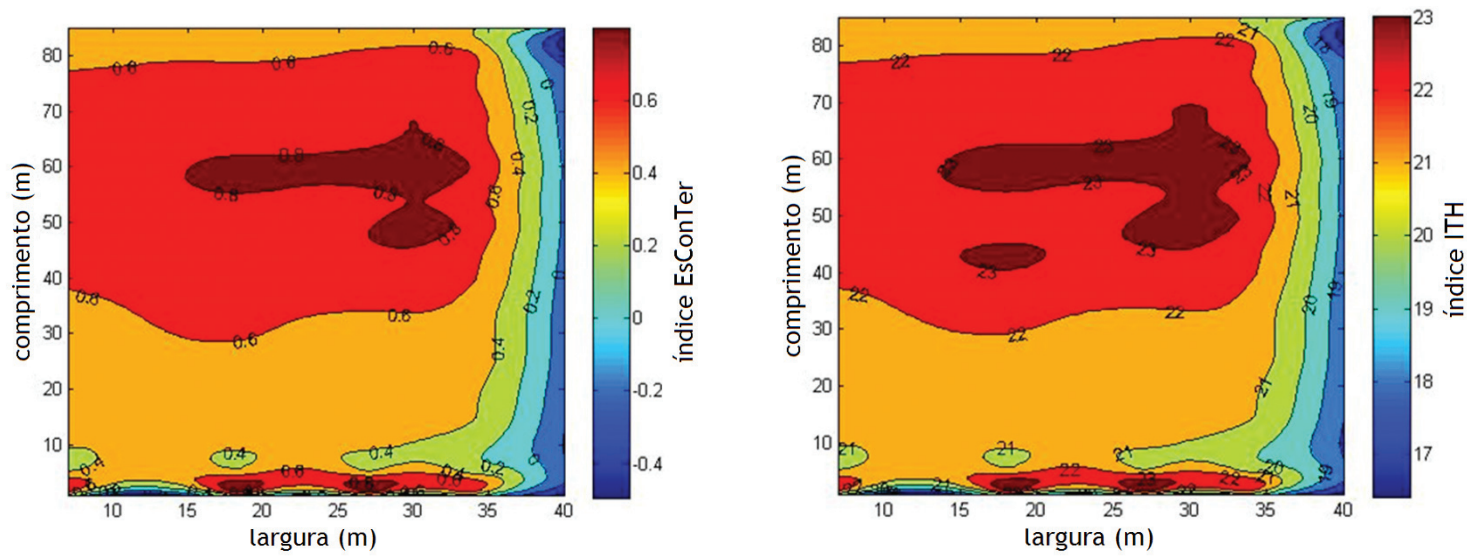

Fig. 4 - Índice EsConTer e Índice ITH $\left({ }^{\circ} \mathrm{C}\right), 6$ de Maio de 2013.

Fig. 4 - EsConTer index and THI index $\left({ }^{\circ} \mathrm{C}\right), 6^{\text {th }}$ of May 2013. 
No que diz respeito ao índice EsConTer, a área com maior desconforto térmico está associada a valores de cerca de 0.8 , muito próximo de $1.0 \mathrm{e}$, por isso, a um ambiente térmico moderadamente quente, representado no modelo PMV-PPD (ASHRAE, 2001), como uma situação onde cerca de $20 \%$ da população está insatisfeita com as condições térmicas.

Relativamente ao índice ITH, as áreas de maior desconforto térmico são as mesmas retratadas no índice EsConTer, contudo, são avaliadas segundo uma escala diferente. Neste índice os valores de maior desconforto térmico atingem cerca de $23^{\circ} \mathrm{C}$, o que significa, de acordo com os intervalos definidos na TABELA II, que os trabalhadores se encontram termicamente confortáveis. Segundo esta classificação, este cenário encontra-se dentro dos parâmetros considerados de conforto térmico, no entanto, muito próximos do limite, $24^{\circ} \mathrm{C}$, que suscita trabalhadores fora do conforto térmico. Para esta zona mais vulnerável a desconforto térmico foi aplicado um algoritmo de zoom, também desenvolvido em Matlab, obtendo-se os gráficos, de pormenor, representados na fig. 5 .

Com a visualização dos gráficos da fig. 5 pode observarse com maior exatidão as zonas com mais desconforto térmico e perceber melhor a dinâmica do ambiente térmico nas zonas de risco. A região que se encontra entre os $57 \mathrm{~m}$ e $62 \mathrm{~m}$ do eixo dos yy e entre os $28 \mathrm{~m}$ e $32 \mathrm{~m}$ do eixo dos $x x$, sugere uma zona de maior atenção para o Departamento de Higiene e Segurança da indústria.

As áreas de maior desconforto térmico são coincidentes no índice EsConTer e no índice ITH, revelando a forte concordância entre os dois índices, comprovada através do método do DMQ (Desvio Médio Quadrático) com um coeficiente de correlação de Pearson de 0.9634. Neste sentido, os dois índices sugerem a mesma informação, no entanto, como referido, há vantagens na aplicação do índice EsConTer, face ao índice ITH.

Os locais assinalados de 1 a 5 , indicados na fig. 5, representam cinco postos de trabalho (TABELA $V$ ) que se localizam na área de estudo e que suscitavam maior

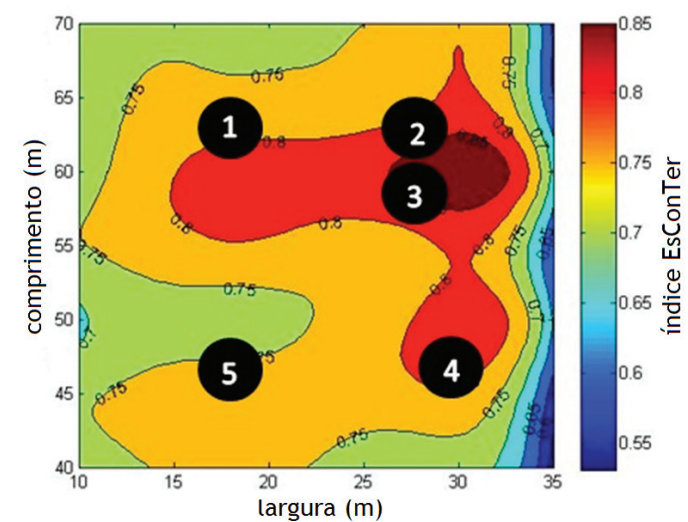

Fig. 5 - Zoom de postos de trabalho mais críticos; Índice EsConTer e Índice ITH $\left({ }^{\circ} \mathrm{C}\right), 6$ de Maio de 2013.

Fig. 5 - Zoom in on workplaces; EsConTer index and THI index $\left({ }^{\circ} \mathrm{C}\right), 6^{\text {th }}$ of May 2013. desconforto térmico, tendo em conta os resultados obtidos neste estudo e a observação in situ.

Em cada um dos cinco postos indicados na fig. 5 foi avaliada a sensação térmica real dos trabalhadores, com a aplicação da escala térmica de cores. Todos os cinco postos de trabalho estão associados a fontes de calor gratuitas como mostra a TABELA $V$, e, para além disso, são também caracterizados por posições de trabalho em pé e um tipo de trabalho mediano, isto é, associado a uma taxa de calor metabólico mínima e por unidade de área de aproximadamente $93 \mathrm{~W} / \mathrm{m}^{2}$ ou 1.6 met (Candas, 2000).

TABela V - Descrição dos postos de trabalho.

$T_{A B L E} V$ - Workplaces' description.

\begin{tabular}{|c|c|}
\hline Posto & Descrição \\
\hline 1 & Posto soldadura manual \\
\hline 2 & Soldadura automática \\
\hline 3 & Entrada do forno \\
\hline 4 & $\begin{array}{c}\text { Montagem de peças- perto da região de } \\
\text { banhos quentes }\end{array}$ \\
\hline 5 & $\begin{array}{c}\text { Zona de montagem de peças - perto da } \\
\text { região de banhos quentes }\end{array}$ \\
\hline
\end{tabular}

No que diz respeito ao vestuário, o clo, calculado através da ISO 7730 (2005), variou entre 0.49clo e 0.69clo, sendo que a $80 \%$ dos inquiridos correspondia um clo igual a 0.54 que caracteriza a farda de trabalho dos trabalhadores do shop floor (polo de manga curta, calças e sapatilhas de biqueira de aço). Tendo em conta o sexo, verificou-se que cerca de $80 \%$ das mulheres inquiridas apresentaram um clo cerca de $28 \%$ superior ao dos homens, devido ao uso de um casaco ou um polo de manga comprida.

A partir dos valores previstos pelo índice EsConTer e das respostas dadas pelos trabalhadores na escala de sensação térmica de cores, foram gerados os gráficos indicados na fig. 6. A observação dos gráficos mostra a variação da sensação térmica real dos trabalhadores e a sensação térmica prevista pelo índice EsConTer para os

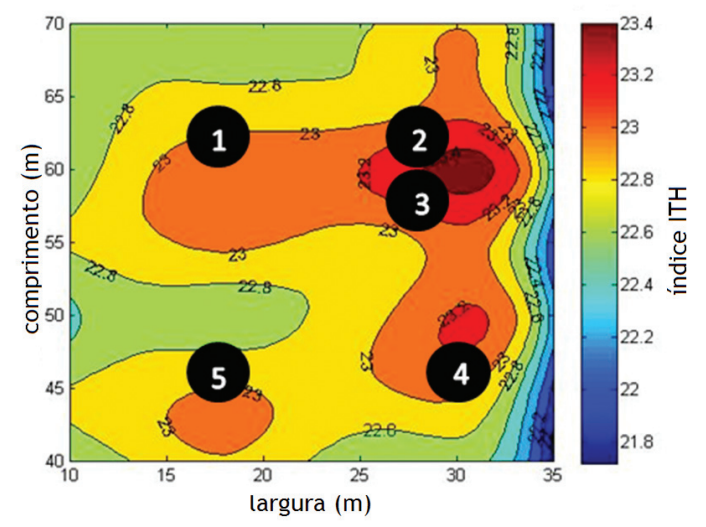


vários postos de trabalho, ao longo do tempo, nos dois turnos estudados.

A observação da fig. 6 (superior) mostra círculos de cor azuis que indicam a sensação térmica prevista no exterior da indústria, os círculos de cor laranja indicam a sensação térmica prevista no interior da indústria e as restantes figuras geométricas com diferentes cores identificam a resposta dada pelo trabalhador em relação à sua sensação térmica real. 0 mesmo raciocínio para a figura inferior (nesta não está a informação dos círculos de cor azuis por não se terem feito registos).

A observação da fig. 6 mostra, ainda, que em ambas as avaliações, cerca das $10 \mathrm{~h} 00$ e cerca das $12 \mathrm{~h} 00$, os valores de sensação térmica dos trabalhadores estão muito próximos dos valores do EsConTer interior. É de realçar que seria certamente impossível obter todos os valores de sensação térmica dos trabalhadores coincidentes com os valores do EsConTer interior visto que a sensação térmica de um indivíduo é muito particular e pode diferir de pessoa para pessoa pelo facto de estar associada a diversos aspetos pessoais. Por exemplo, na primeira avaliação os valores da sensação térmica do trabalhador OP_02 mostram-se particularmente distantes dos outros trabalhadores, com um valor próximo de 1.0, o que realça a subjetividade inerente a esta variável. No turno da manhã verifica-se que o ambiente externo à nave, representado pelo EsConTer exterior, não variou significativamente nas duas avaliações. Neste sentido, verificou-se também que o EsConTer interior se manteve em todos os casos com valores muito próximos ao longo deste período, entre 0.4 e 0.8 na primeira avaliação e de 0.4 a 0.6 na segunda avaliação. Por outro lado, também se verifica que o EsConTer interior é sempre superior ao EsConTer exterior devido ao isolamento da infraestrutura e a toda a dinâmica do espaço, seja ela de pessoas, máquinas e/ou ferramentas.

O turno da tarde mostrou um ambiente térmico ligeiramente mais quente, com particular realce para cerca das $16 \mathrm{~h} 30$. Uma justificação está associada ao efeito de estufa gerado no interior da nave, no entanto as mesmas ilações podem ser retiradas em relação às sensações térmicas reais dos trabalhadores.

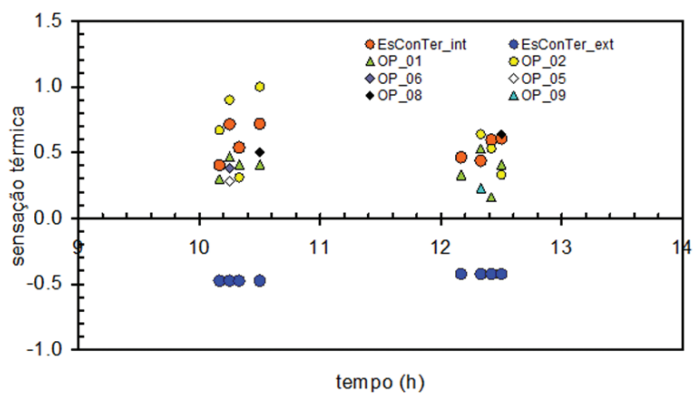

Os dados registados e calculados foram ainda trabalhados e interpretados usando a plataforma CBE Thermal Comfort Tool. A vantagem desta plataforma está no facto de avaliar as características térmicas das áreas consideradas mais vulneráveis e conhecer sugestões para o melhoramento das condições de trabalho. As considerações retiradas foram comparadas com a informação retirada da aplicação do índice EsConTer e da escala térmica de cores.

Na fig. 7 está representada a área de maior risco de desconforto térmico, o círculo de cor "vermelho escuro" que está associado ao índice EsConTer (ver fig. 5, EsConTer 0.8 , temperatura do $\operatorname{ar} 26^{\circ} \mathrm{C}$ e humidade relativa do ar $45 \%)$. Estes dois últimos valores foram inseridos no input da plataforma, assim como os valores do metabolismo e do isolamento térmico (1.6met e $0.54 \mathrm{clo})$.

Os resultados da plataforma, desenhados na cor "azul" para a condição de conforto térmico, mostraram que os dados inseridos como inputs não estão de acordo com a informação ASHRAE Standard 55-2010, apresentando desconforto térmico quente associado ao valor de PMV de 0,94 (ligeiramente quente) e a uma percentagem de pessoas insatisfeitas de 24\% (PPD). Nestas circunstâncias a interpretação retirada está em concordância com o índice EsConTer (0.80 a 0.85).

Como sugestão a plataforma parece indiciar que devem ser valorizadas pelo Departamento de Higiene e Segurança estratégias corretivas de intervenção.

\section{O caso da Indústria 2}

Para o estudo da indústria 2 escolheu-se aleatoriamente o dia 10 de Abril de 2014 para representar, neste trabalho, o padrão térmico. A fig. 8 representa o padrão da temperatura do ar e da humidade relativa no espaço em estudo. A região afetada por temperaturas do ar mais elevadas corresponde à área onde se encontra o forno, a qual devido à energia radiante é a região onde se sente maior desconforto térmico. Estas regiões afetadas por temperaturas do ar mais elevadas correspondem às regiões com humidade relativa do ar mais baixa, como seria esperado.

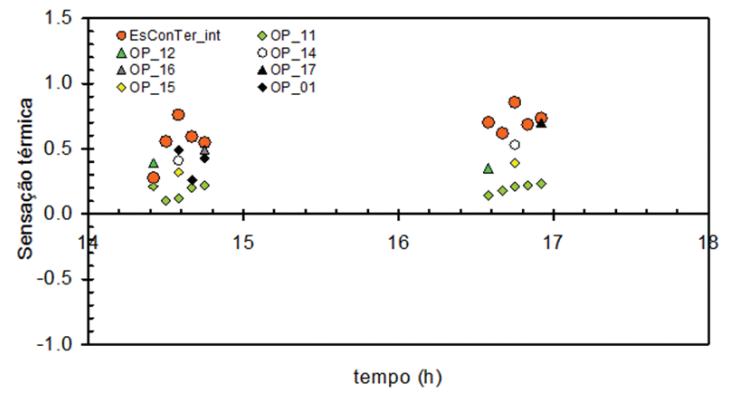


Os gráficos da fig. 9 representam o padrão do espaço interior quando se aplicam os índices térmicos EsConTer e ITH. O valor do índice EsConTer mostra-se de uma forma geral alto, registando o pico de 1.8.

Tendo em conta a interpretação do índice EsConTer, os valores de 0.4 a 1.2 sugerem algum desconforto térmico, nomeadamente acima de 0.5 (ambiente moderado a ligeiramente quente). Segundo o modelo PMV-PPD a percentagem de pessoas insatisfeitas neste intervalo pode variar entre $8 \%$ e $30 \%$.

O padrão segundo a aplicação do índice ITH mostrase, mais uma vez, concordante com o padrão obtido pela aplicação do índice EsConTer, apresentando um coeficiente de correlação de Pearson de 0.9954.

$\mathrm{Na}$ fig. 10 estão representados os gráficos de superfície de cor Zoom da fig. 9 gerados em Matlab de forma a perceber melhor o padrão do espaço em redor da máquina de trabalho termicamente mais critica, o forno.
Assim, tendo em conta a posição do forno, destaca-se a área com os postos de trabalhos com maior risco a desconforto térmico na gama de 0.4 a 1.0 para o índice EsConTer e na gama de $21^{\circ} \mathrm{C}$ a $24^{\circ} \mathrm{C}$ para o índice ITH. Nos gráficos estão indicados os 8 postos de trabalho, numerados de 1 a 8 , mais vulneráveis. Na TABELA VI estão caracterizados esses postos de trabalho em termos da função de operação.

A sensação térmica real destes oito trabalhadores (todos do sexo masculino) foi avaliada e apresentou um valor de 0.44 clo a 0.49 clo (um tipo de vestuário que considera calções ou calças finas, cueca, camisola de manga curta fina, sandálias ou sapatilhas e meias). Relativamente ao Metabolismo dos trabalhadores, este foi avaliado em função da atividade, como se mostra na TABELA VII.

A fig. 11 mostra a sensação térmica real dos trabalhadores no período da manhã e no período da tarde. Estes gráficos dizem respeito a um dia de medições escolhido aleatoriamente, o dia 9 de Maio de 2014. O EsConTer
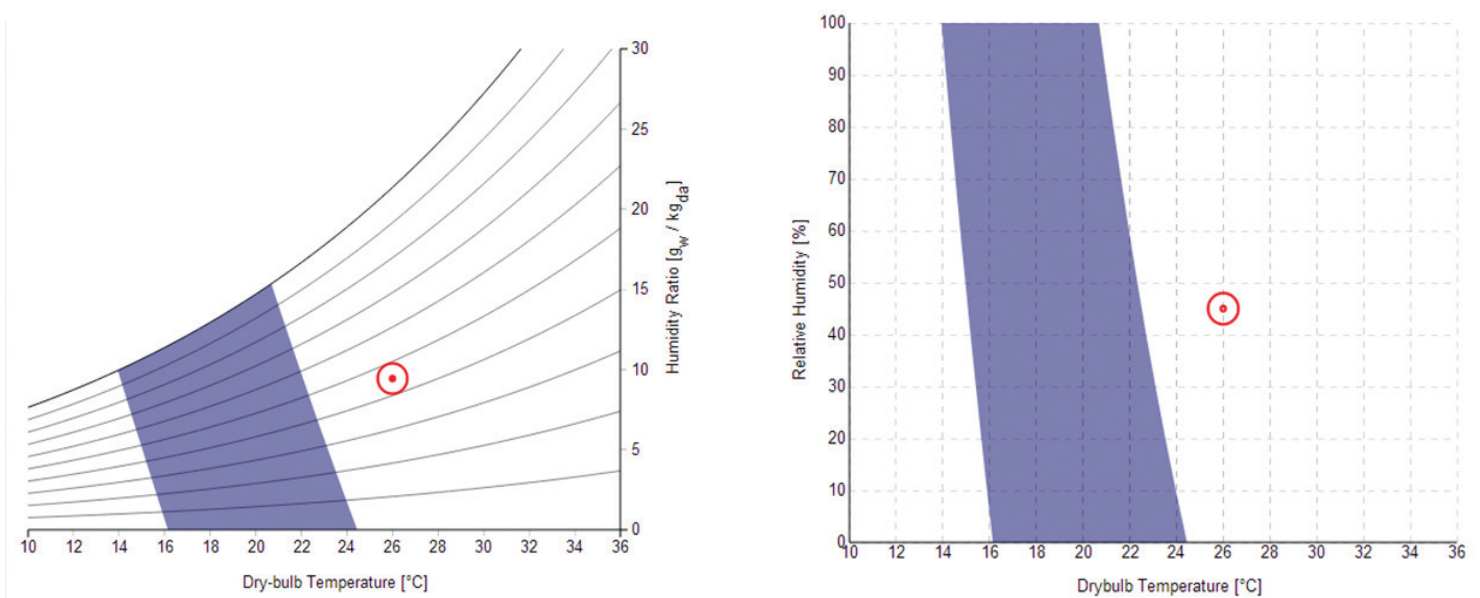

Fig. 7 - CBE Thermal comfort tool para a região de maior desconforto térmico- gráfico temperatura do ar e gráfico temperatura do arhumidade relativa do ar.

Fig. 7 - CBE Thermal comfort tool for the most uncomfortable area: air temperature - humidity ratio chart and air temperature-air relative humidity chart.
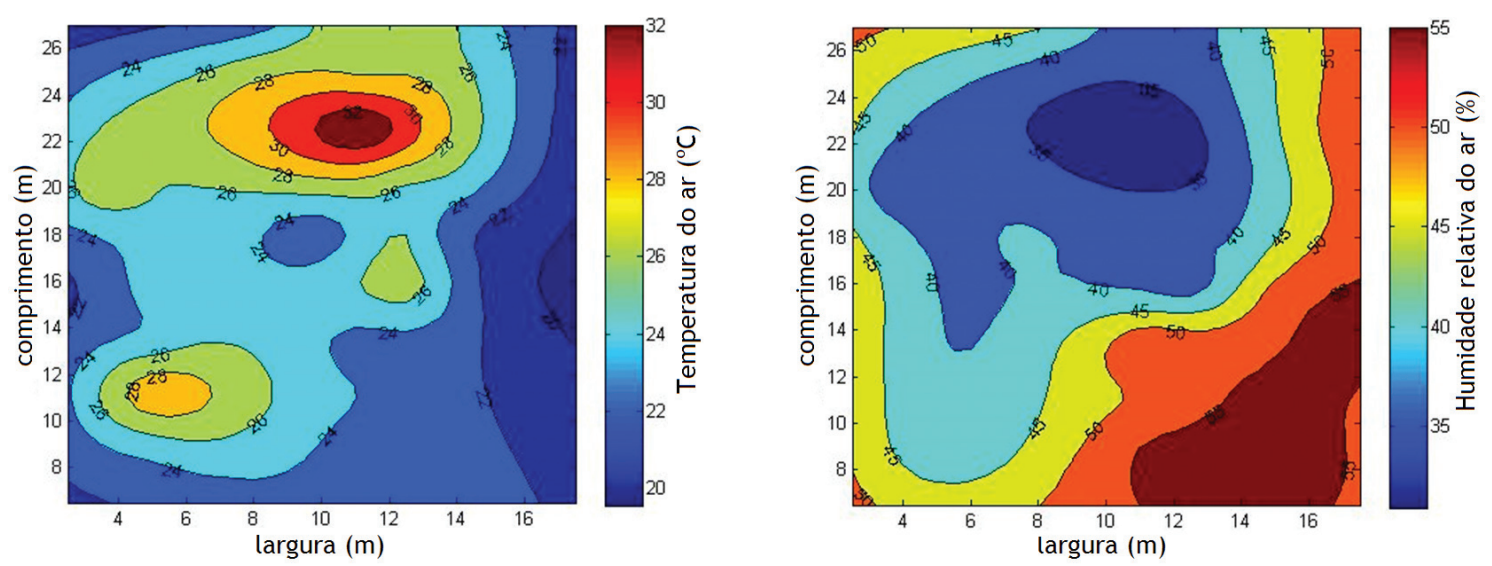

Fig. 8 - Temperatura do ar $\left({ }^{\circ} \mathrm{C}\right)$ e Humidade Relativa do ar (\%), 10 de Abril de 2014.

Fig. 8 - Air temperature $\left({ }^{\circ} \mathrm{C}\right.$ ) and air relative humidity (\%), $10^{\text {th }}$ of April 2014. 
interior mostra que o ambiente térmico interior do espaço se tornou ligeiramente mais quente no período da tarde, quando comparado com o período da manhã. 0 ambiente externo, representado pelo EsConTer exterior manteve a mesma tendência.

Os valores de sensação térmica real dos trabalhadores mostraram-se concordantes com o ambiente térmico devido à proximidade de valores previstos para o EsConTer interior. No entanto, tal como previsto

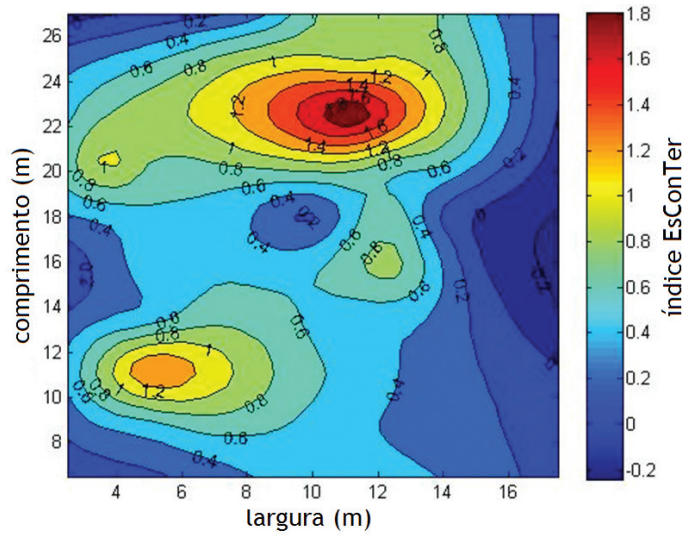

alguns trabalhadores apresentaram valores mais discrepantes associados à subjetividade da sensação térmica, como são exemplo, o trabalhador OP_12 na primeira avaliação (10h00), o trabalhador OP_13, no momento de avaliação das $12 \mathrm{~h} 00$ e o trabalhador OP_18 no turno da tarde.

Nesta indústria também foi usada a plataforma CBE Thermal Comfort Tool. À semelhança da indústria 1 escolheu-se a área com maior risco identificada pelo

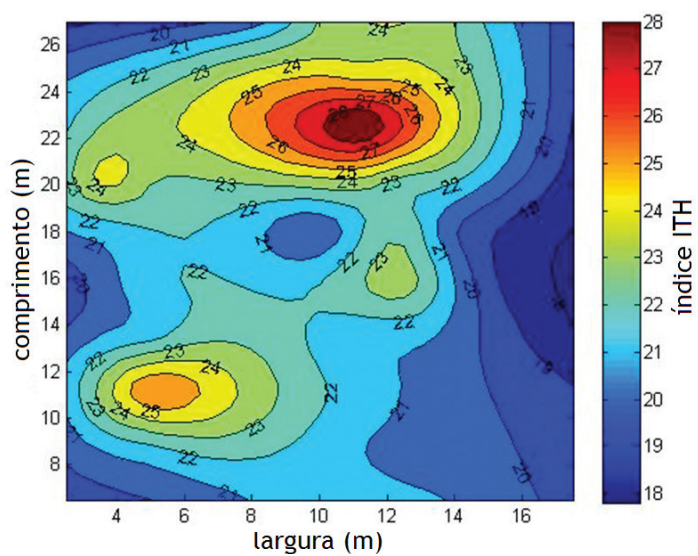

Fig. 9 - Índice EsConTer e Índice ITH $\left({ }^{\circ} \mathrm{C}\right), 10$ de Abril de 2014.

Fig. 9 - EsConTer index and THI index $\left({ }^{\circ} \mathrm{C}\right), 10^{\text {th }}$ of April 2014.
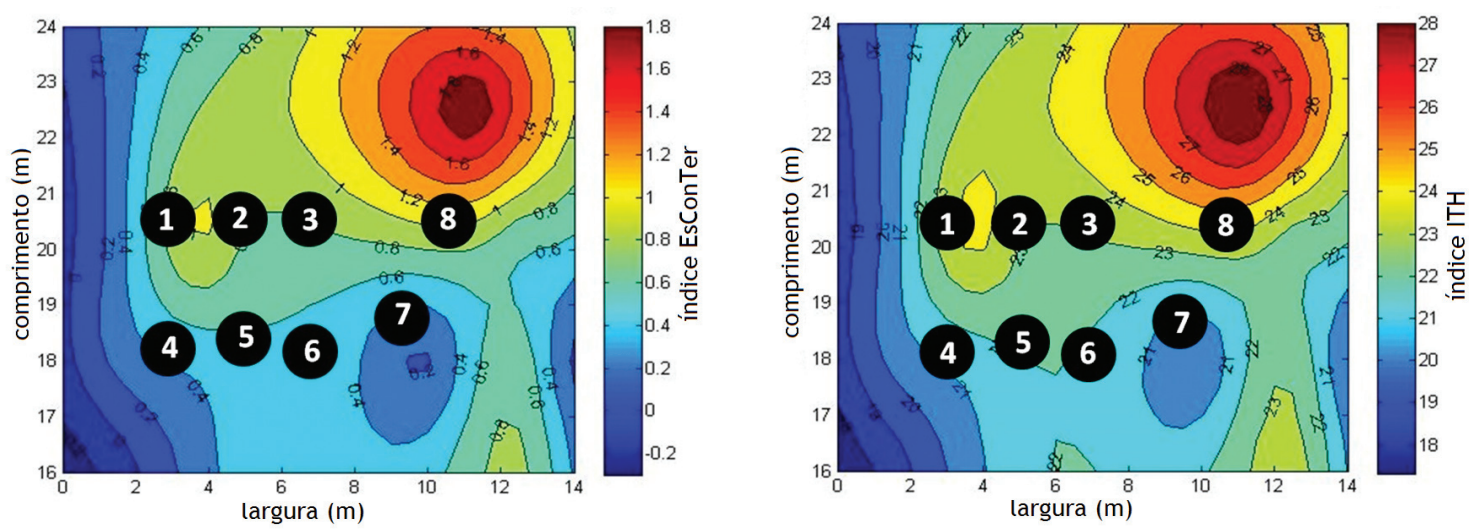

Fig. 10 - Zoom - postos de trabalho mais críticos e o Índice EsConTer e Índice ITH $\left({ }^{\circ} \mathrm{C}\right)$, 10 de Abril de 2014.

Fig. 10 - Zoom in on workplaces; EsConTer index and THI index $\left({ }^{\circ} \mathrm{C}\right), 10^{\text {th }}$ of April 2014.

TABELA VI - Descrição dos postos de trabalho

TABLE VI - Workplaces' description.

\begin{tabular}{|c|c|}
\hline Posto & Descrição \\
\hline 1 & Corte a quente \\
\hline 2 & Prensa \\
\hline 3 & Boca do forno 1 - recolha do vidro \\
\hline 4 & Levar a cima \\
\hline 5 & Prensa e corte a quente \\
\hline 6 & Boca do forno 2 - recolha do vidro \\
\hline 7 & Boca do forno 3 - recolha do vidro \\
\hline 8 & Boca do forno 4 - recolha do vidro \\
\hline
\end{tabular}

TABELA VII- Metabolismo (aproximado) associado a cada posto de trabalho [cálculo baseado em (V. Candas, 2000)]

$T_{\text {ABLE }}$ VII - Metabolism (approximation) associated to each workplace [calculation based on (V. Candas, 2000)].

\begin{tabular}{|c|c|}
\hline Posto & Taxa de Metabolismo $\left(\mathrm{W} / \mathrm{m}^{2}\right.$ - met) \\
\hline 1 & $93-1,60$ \\
\hline 2 & $93-1,60$ \\
\hline 3 & $145-2,49$ \\
\hline 4 & $87-1,49$ \\
\hline 5 & $93-1,60$ \\
\hline 6 & $145-2,49$ \\
\hline 7 & $145-2,49$ \\
\hline 8 & $145-2,49$ \\
\hline
\end{tabular}


índice EsConTer a desconforto térmico como input. Neste caso é apresentada a zona a cor "verde" da fig. 10 delimitada pelo valor 0.8 do índice EsConTer, onde estão localizados alguns dos postos de trabalho (1, 2, 3 e 8). Foram inseridos como inputs o valor da temperatura do ar (igual à temperatura média radiante) $26^{\circ} \mathrm{C}$, da humidade relativa do ar $35 \%$, do metabolismo 1.6 met e do isolamento térmico associados aos trabalhadores $0.44 \mathrm{clo}$.

Os gráficos representados na fig. 12 apresentam os resultados obtidos pela aplicação da plataforma, considerando o ambiente térmico mais uma vez, e como era esperado, em desacordo com a ASHRAE Standard 55-2010 e de acordo com o índice EsConTer. Na prática há um desconforto térmico associado ao valor de PMV de 0,77 (ligeiramente quente) e a uma percentagem de pessoas insatisfeitas de 17\% (PPD).

A área de cor azul traçada no gráfico da fig. 12 diz respeito à zona de conforto térmico sugerida pela plataforma tendo em conta os inputs introduzidos, nomeadamente os pessoais, vestuário e metabolismo. Tal como na indústria 1 , a indústria 2 também está longe das condições ótimas para satisfazer o maior número de pessoas afetas aos postos de trabalho localizados na região de maior risco a desconforto térmico.

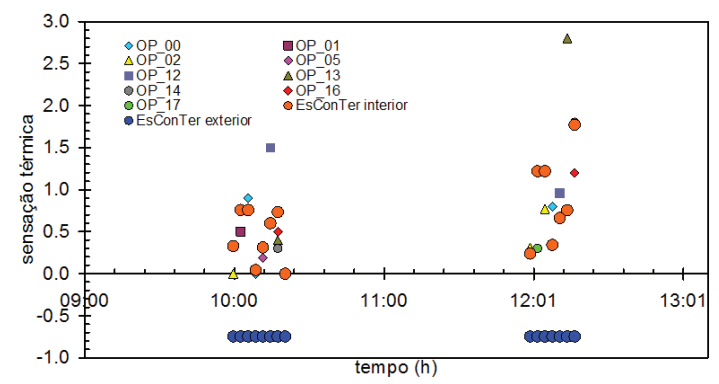

Fig. 11 - Sensação térmica prevista e real dos trabalhadores no turno da manhã e no turno da tarde.

Fig. 11 -Workers' predicted and real thermal sensation in morning and afternoon shift.
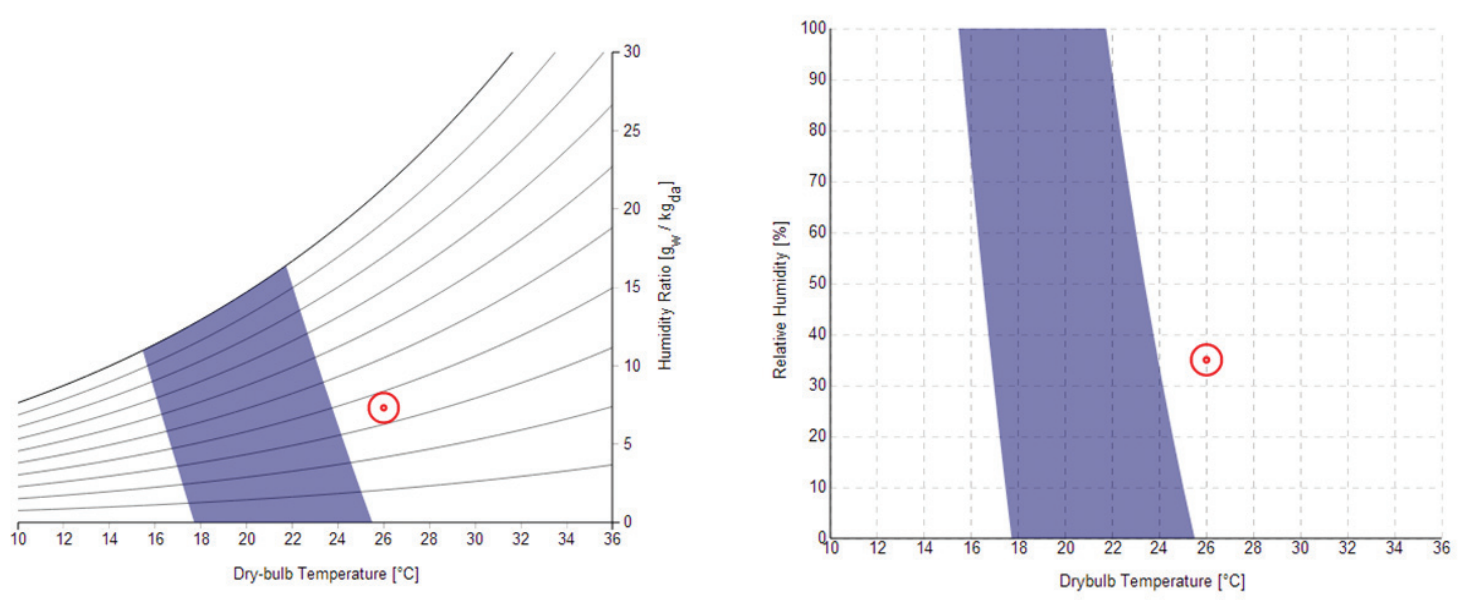

Fig. 12 - CBE Thermal comfort tool para a região de maior desconforto térmico- gráfico temperatura do ar e gráfico temperatura do ar- humidade relativa do ar.

Fig. 12 - CBE Thermal comfort tool for the most uncomfortable area: air temperature - humidity ratio chart and air temperature-air relative humidity chart.
Os resultados obtidos foram valorizados para a implementação da redução do risco de stress térmico nas duas indústrias e pelo Departamento de Higiene e Segurança. Uma das soluções passou pela alteração da implantação de máquinas e protecção de energia radiante directa.

\section{Conclusão}

Os dois casos de estudo apresentados neste trabalho, apesar de terem sido abordados em contextos industriais muito distintos no que diz respeito ao ramo de atividade, localização, infraestruturas, condições e ferramentas de trabalho, mostraram resultados bastante interessantes e semelhantes num ambiente térmico quente.

Os mapas de superfície de cor desenvolvidos em Matlab mostraram ser uma ferramenta bastante intuitiva no que diz respeito à compreensão do padrão térmico do espaço tendo em conta a representação espacial dos espaços em estudo.

A partir das ferramentas de estudo utilizadas foi possível compreender o padrão térmico previsto dos dos trabalhadores. 0 índice EsConTer e o índice ITH mostraram-se capazes de traduzir o padrão do ambiente

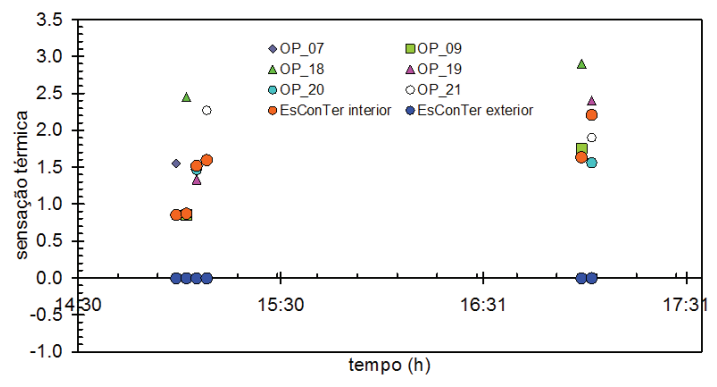
espaços industriais, assim como a sensação térmica real 
térmico evidenciando com clareza os locais com maior vulnerabilidade a risco de desconforto térmico. 0 índice EsConTer, desenvolvido por (M. Talaia et al., 2009) mostrou ser uma ferramenta de fácil aplicação e de fácil interpretação do ambiente térmico. Neste sentido, sugere-se que o índice EsConTer seja valorizado em contexto industrial em estudos futuros de ambientes térmicos quentes, assim como a escala térmica de cores (M. Talaia e H. Simões, 2008). Os resultados obtidos revelaram ainda que o índice EsConTer prevê uma sensação térmica muito próxima à sentida pelos trabalhadores.

Os resultados da plataforma CBE Thermal Comfort Tool mostraram-se sempre concordantes com o índice EsConTer sugerindo que esta ferramenta possa ser interessante para tomar decisões, não ao nível do padrão térmico, devido à representação gráfica, mas para tentar encontrar soluções locais, a partir do intervalo de conforto sugerido pela mesma. Pois, cada local do espaço é ocupada por pessoas diferentes, a desenvolver tarefas diferentes com máquinas e/ou ferramentas diferentes e, por isso, é importante, para além do reconhecimento do tipo de ambiente térmico geral de um espaço, ter um conhecimento específico de todos os locais do espaço, visto que nem sempre é necessário atuar num espaço completo, mas apenas num local ou posto de trabalho específico.

No que diz respeito às duas indústrias em estudo, como esperado o padrão térmico da indústria 2 mostrou ser de um ambiente térmico mais quente do que o padrão térmico da indústria 1 devido ao ramo de atividade e tipo de tarefas desempenhadas nos postos de trabalho. Quanto ao isolamento do vestuário, verifica-se também que os trabalhadores da indústria 2 apresentam vestuário associado a valores de clo mais baixos que os trabalhadores da indústria 1. Esta situação é aceitável e compreensível, uma vez que a indústria 2 , como já foi referido, está sujeita a ambientes térmicos que sugerem maior risco a desconforto térmico. Neste sentido, os trabalhadores da indústria 2 também apresentaram sensações térmicas mais desconfortáveis que os trabalhadores da indústria 1.

Em suma, a abordagem do ambiente térmico dos espaços selecionados e abordados mostrou ser suficiente e eficaz na identificação de zonas de maior risco a desconforto térmico, sendo o índice EsConTer um índice térmico bastante versátil, sugerindo uma boa representação do padrão térmico de um espaço interior e por sua vez um bom preditor da sensação térmica de indivíduos.

Os resultados obtidos nos dois espaços foram considerados pelo Departamento de Higiene e Segurança de cada indústria, tendo em vista a implementação de medidas que possam satisfazer as necessidades de conforto térmico dos trabalhadores, reduzindo riscos de fadiga e acidentes de trabalho e aumentando índices de qualidade, segurança e produtividade.

\section{Bibliografia}

Akimoto, T., Tanabe, S., Yanai, T., \& Sasaki, M. (2010). Thermal comfort and productivity. Evaluation of workplace environment in a task conditioned office. Building and Environment, 45(1), p. 4550. Doi:10.1016/j.buildenv.2009.06.022

Araújo, M. E., Arezes, P., \& Braga, A. C. (2013). Working Memory in Moderate Thermal Environments : A Field Study. In Sho'13-International Symposium on Occupational Safety and hygiene. Guimarães, Portugal.

ASHRAE. (2001). Thermal Comfort. In American Society of Heating, Refrigerating and Air-Conditioning Engineers (2001 ASHRA.). Colorado 80112-5776 USA: Englewood.

ASHRAE 55. (2004). Thermal environmental conditions for human occupancy. American Society of Heating, Refregerating and Air-Conditioning Engineers.

Bakar, R. A, Jusoh, N., Makhtar, N. K., Rahman, M. N. A, \& Meier, C. (2010). Thermal comfort assessment: A case study at Malaysian automotive industry. American Journal of Applied Sciences, 3(8), 1495-1501.

Bluyssen, P. M., Aries, M., \& van Dommelen, P. (2011). Comfort of workers in office buildings: The European HOPE project. Building and Environment, 46(1), p. 280-288. Doi:10.1016/j.buildenv.2010.07.024

Candas, V. (2000). Techniques de l'Ingénieur, traité Génie énergétique. Doc.BE 9085.

Castilla, M., Álvarez, J. D., Berenguel, M., Rodríguez, F., Guzmán, J. L., \& Pérez, M. (2011). A comparison of thermal comfort predictive control strategies. Energy and Buildings, 43(10), p. 2737-2746. doi:10.1016/j. enbuild.2011.06.030

Chow, T. T., Fong, K. F., Givoni, B., Lin, Z., \& Chan, a. L. S. (2010). Thermal sensation of Hong Kong people with increased air speed, temperature and humidity in air-conditioned environment. Building and Environment, 45(10), p. 21772183. Doi:10.1016/j.buildenv.2010.03.016

Daum, D., Haldi, F., \& Morel, N. (2011). A personalized measure of thermal comfort for building controls. Building and Environment, 46(1), p. 3-11. Doi:10.1016/j.buildenv.2010.06.011

Djongyang, N., Tchinda, R., \& Njomo, D. (2010). Thermal comfort: A review paper. Renewable and 
Sustainable Energy Reviews, 14(9), p. 26262640. Doi:10.1016/j.rser.2010.07.040

Emmanuel, R. (2005). Thermal comfort implications of urbanization in a warm-humid city: the Colombo Metropolitan Region (CMR), Sri Lanka. Building and Environment, 40, p. 1591-1601. Doi:10.1016/j.buildenv.2004.12.004

Fanger, P. (1972). Thermal Comfort (2nd editio.). New York: McGraw-Hill.

Felix, V. B., Moura, D., Pereira, M. L., \& Tribess, A. (2010). Evaluation of thermal comfort in surgical environments using Fanger's method and equivalent temperatures. Ambiente Construído, 10, p. 69-78.

Hoppe, P. (2002). Different aspects of assessing indoor and outdoor thermal comfort. Energy and Buildings, 34, p. 661-665.

Huang, J. (2006). Thermal parameters for assessing thermal properties of clothing. Journal of Thermal Biology, 31, p. 461-466.

Huizenga, C., Abbaszadeh, S., Zagreus, L., \& Arens, E. (2006). Air Quality and Thermal Comfort in Office Buildings: Results of a Large Indoor Environmental Quality Survey. In Proceedings of Healthy Buildings, p. 393-397, Lisbon.

ISO 7730. (2005). Ergonomie des ambiances thermiquesDétermination analytique et interprétation du confort thermique par le calcul des indices PMV et PPD et par des critères de confort thermique local. (International Standardization Organization, Ed.). Geneva, Suisse.

Lin, T.P., Matzarakis, A., \& Hwang, R.-L. (2010). Shading effect on long-term outdoor thermal comfort. Building and Environment, 45(1), p. 213-221. Doi:10.1016/j.buildenv.2009.06.002

Liu, J., Yao, R., Wang, J., \& Li, B. (2012). Occupants' behavioural adaptation in workplaces with non-central heating and cooling systems. Applied Thermal Engineering, 35, p. 40-54. Doi:10.1016/j.applthermaleng.2011.09.037

Meles, B. A. (2012). Ergonomia Industrial e Conforto Térmico em postos de trabalho. Universidade de Aveiro.

Morgado, M., Talaia, M., \& Teixeira, L. (2014). Conforto térmico na construção de ambientes de saúde e segurança: revisão da literatura. In Multidimensão e territórios de risco, III Congresso Internacional, I Simpósio IberoAmericano e VIII Encontro Nacional de Riscos. Guimarães, Portugal.
Nieuwolt, S. (1977). Tropical climatology. London.

Nogueira, J., \& Talaia, M. (2014). Influence of hot thermal environment in practice of Aerostep. In ... G. Perestrelo P. Arezes, J. S. Baptista, M. P. Barroso, P. Carneiro, P. Cordeiro, N. Costa (Ed.), Occupational Safety and Hygiene, p. 473477. London: CRC Press Taylor \& Francis group.

Parsons. (2003). Human Thermal Environments: The Effects of Hot, Moderate and Cold Environments on Human Health, Comfort and Performance. In Taylor \& Francis (Eds.).

Parsons, K. (2000). Environmental ergonomics: a review of principles, methods and models. Applied Ergonomic, p. 581-594.

Pereira, D. (2013). Climatic process and their effects on thermal dissipation in classrooms at public schools. In Sho'13-International Symposium on Occupational Safety and hygiene. Guimarães, Portugal.

Pinheiro, I. P. T. (2011). Conforto Térmico e BemEstar numa Superfície Comercial Isolada. Universidade do Porto.

Riniolo, T. C., \& Schmidt, L. A. (2006). Chronic heat stress and cognitive development: An exemple of thermal conditions influencing human development. Developmental Review, 26, p. 277-290.

Rodrigues. (2007). Conforto e Stress Térmico: uma Avaliação em Ambiente Laboral. Univ. de Aveiro.

Rodrigues, B. (1978). A Bioclimatologia e a Produtividade Laboral. Revista Do Instituto Nacional Meteorologia Geofísica (Volume 1), p. 39-51.

Schiavon, S., Hoyt, T., \& Piccioli, A. (2014). Web application for thermal comfort visualization and calculation according to ASHRAE Standard 55. Building Simulation, 7, p. 321-334. Doi:10.1007/s12273-013-0162-3

Starling, Mendonça, V., Alsina, O., \& Monteiro, L. (2013). Ergonomic Analysis at a Working Station Located in a Technology an Information Management Company from Sergipe, Brazil, Based on Temperature and Termic Stress Level. In Sho'13-International Symposium on Occupational Safety and hygiene, p. 403-404. Guimarães, Portugal.

Talaia, M., \& Rodrigues, F. (2008). Conforto e stress térmico: uma avaliação em ambiente laboral. In Gomes et al. Edição INEGI (Ed.), CLME'2008 II CEM. $8^{\circ}$ Congresso Luso-Moçambicano de engenharia e $2^{\circ}$ Congresso de Engenharia de Moçambique, Maputo, p. 15. 
Talaia, M., \& Simões, H. (2009). EsConTer: um índice de avaliação de ambiente térmico. In V Congresso cubano de Meteorologia, p. 1612-1626. SometCuba, Sociedade de Meteorologia de Cuba.

Tavares, I. (2014). Avaliação de ambiente frio e sensação térmica de trabalhadores: estudo de caso numa empresa de bacalhau (Dissertação de tese de mestrado). Universidade de Aveiro.

Teixeira, L., Talaia, M., \& Morgado, M. (2014). Evaluation of indoor thermal environment of manufacturing industry. In M. P. Azeres,
J. Baptista, M. Barroso, P. Carneiro, P. Cordeiro, N. Costa, ... G. Perestrelo (Eds.), Occupational Safety and Hygiene II, p. 553-558. London, UK: CRC Press Taylor \& Francis group.

Thom, E. C. (1959). The Discomfort index. In Weatherwise (pp. 57-60). Boston.

Yao, R., Li, B., \& Liu, J. (2009). A theoretical adaptive model of thermal comfort - Adaptive Predicted Mean Vote (aPMV). Building and Environment, 44(10), p. 2089-2096. Doi:10.1016/j. buildenv.2009.02.014. 